\title{
Recycling of Mineral Water Bottles with Chemical Foaming
}

\author{
V. A. SZABÓ, G. DOGOSSY \\ Széchenyi István University, Department of Materials Science and Technology \\ H-9026, Győr, Egyetem tér 1, Hungary \\ Phone: +36 96503400 \\ e-mail: szabpanka@gmail.com; dogossy@sze.hu
}

\begin{abstract}
Today, in the field of packaging technologies there is an increasing amount of one-way polymer materials. Such materials after their short lifecycle are disposed, and such pose a serious environmental impact. However, PET is a good quality technical plastic; the recycled use must be provided. In our research, we have examined the recycled material of mineral water bottles. Chemical foaming of recycled polyethylene terephthalate (rPET) was applied for quality increased reusability. Significant results were achieved in terms of mechanical properties at specific mixtures of chain extender and impact resistance enhancer, at the foaming state of the injection moulding.
\end{abstract}

Keywords: rPET; recycling; chemical foaming; chain extender; polymer foam

\section{Introduction}

In the 1950's the consumption of fossil based raw materials rapidly grown along with the use of energy carriers. This attracted the rapid growth of the plastics industry. In 1970 the polyethylene terephthalate (PET) has been released and soon began to dominate the market for liquid foods packaging; consumer habits have changed. Due to low production costs, low weight, good optical properties and gas tightness PET has outperformed glass.

Due to the widespread use, PET waste will be projected to reach 29 million tonnes a year by 2018. As an effect of its mechanical and chemical properties, its resistance to chemicals and radiations is outstanding. At the same time this results in the natural decomposition of more than 450 years [1].

In this research work, technical properties of the PET will be presented that have become waste, in order to expand the possibility of secondary utilization. PET that has been discarded is still a good quality technical plastic; that can prove to be a major player in the future of raw materials.

During the production of the bottles, the preforms are placed in a stretching blower that warms them in a formable state in seconds. They are stretched longitudinally with a rod, and at the same time air is blown at high pressure, pushing the plastic to the bottle-shaped 
metal mould wall. After the cooling, the shaping process is carried out. When the bottles are recycled, the chain structure of the PET is broken. The primary goal is to reverse the process, to improve the mechanical and physical properties of the recycled substance [2]. Various natural and synthetic raw materials were examined as to how effective they can be applied as chain extenders. During this work, the chosen manufacturing technology is injection moulding; by the change of the technological parameters of the moulding the change on the internal structure of the product is examined. The goal is to produce a low density material with specific mechanical properties. An examination for the automotive utilization of the raw material created, taking into account the wreckage directive (ELV Directive 2000/53 / EC). The aim of the research is partly environmental protection and partly the innovative technical raw material production [3].

\subsection{Polyethylene terephthalate}

Polyethylene terephthalate is a poly-condensation product of terephthalic acid and ethylene glycol (Fig. 1). It is currently considered the largest raw material for fibre manufacturing. Under nitrogen atmosphere, in the presence of $\mathrm{Zn}$, Co, $\mathrm{Mn}$ acetate, dimethyldiphthalene with ethylene glycol is trans-esterified. During the reaction, the formation of the polymer is mainly due to gradual depletion.

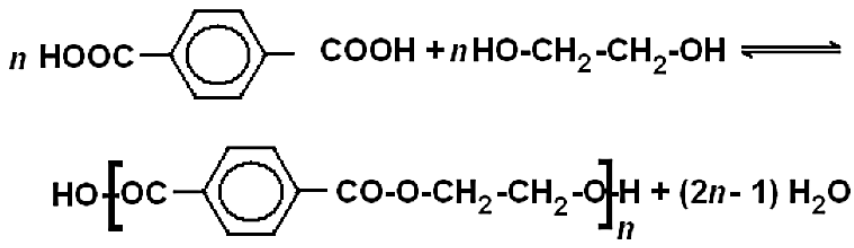

\section{Figure 1. Equation of the production reaction of PET [4]}

PET has high mechanical strength and high heat resistance, which is why crystalline technical plastics are typically used for fiber forming. Its resistance is very high; it is oil, grease, petrol and chemical resistant. Its radiation resistance and weather resistance are also good. Its negative property is to dissolve the alkali, phenol, cresol and its derivatives and destroy the structure of the oxidizing acids [4].

\subsection{Manufacture of PET re-granulate}

The main purpose of selective waste collection is to recycle. Only low-pollutant PET waste can be used for recycling. The recovery of the right raw material for recycling begins with selective waste collection.

Recycling of uncleaned and dry bottles is expensive. It would be an important expectation that we teach children what bottles can be collected at a young age. For example, in the acidic medium, the PET molecules cannot be degraded. Bases are catalyse the degradation of PET molecules. Thus, the acetic and hydrochloric acid bottles in the waste bin will also prevent recycling of other bottles that come into contact with it. One of the regeneration steps of PET mills is cleansing and washing with water. The amount of water can be reduced by appropriate drying, and most be reduced because the presence of water reduces the average molecular weight of the polymer due to hydrolytic reactions. 
PET mills process material in chemical and mechanical methods. Chemically, partial or complete depolymerisation is performed by the addition of water, ethylene glycol and methanol.

- PET mills + water $\rightarrow$ ethylene glycol and terephthalic acid

- PET mills + ethylene glycol $\rightarrow$ bis (hydroxyethyl) terephthalate

- PET mills + methanol $\rightarrow$ dimethyl terephthalate - is formed.

For mechanical processing, the regrind is cleaned, dried and then processed as a thermoplastic, in a melted state [5].

The injection moulding of high quality components from recycled PET is complicated by several factors. During recycling, thermal and shear stresses cause significant degradation, this can be further enhanced by possible contaminants and moisture content. Process-ability is a function of moisture content and should therefore be kept below $0.004 \%$.

As a consequence of recycling, it is a serious problem that its mechanical properties are deteriorating [6,7].

This research is focused on the development of secondary raw materials with recycled PET foaming.

\subsection{Foaming}

Under the term polymer foam, we mean a biphasic system in which statistical distributions of variable gas bubbles are embedded in a polymer matrix. Almost all thermoplastic polymers are suitable for making a foamed product. The foaming processes can be classified into three main groups: mechanical, physical and chemical.

During chemical foaming, the foaming agent forms a gas that foams the plastic structure. Foaming is started after mechanical stirring of the blowing agent. The process is supported by heat transfer. The formation of the foam structure is followed by forming and solidification. During the chemical reaction, various decomposition products are formed (eg. $\mathrm{CO}_{2}$, ammonia, water) [6].

Chemical blowing agents are organic or inorganic solids that decompose in a high temperature melt. Their solid decomposition products act as nucleus. In addition, large quantities of gas are generated. The gas bubbles formed at the nucleus in the coolant melt and form cells.

In the experiment, we combined the traditional injection moulding technology with the breathing- mould technique. The injection moulding cycle of the foamed specimens is as follows:

1. The mould closes.

2. The injection unit closes, connects to the injection-side of the mould.

3. The melted polymers is injected to the mould.

4. Holding pressure is maintained for 3 seconds. 
5. Plastification of the materials for the next cycle.

6. The injection unit opens.

7. Mould breathing (the mould opens until $0.3 \mathrm{~mm}$ ).

8. Cooling for 20 seconds.

9. The mould opens.

10. Ejection of the specimen.

\subsection{PET foaming}

During PET foaming attention must be paid to the material drying, as due to hydrolysis the internal viscosity of the melt decreases; as a direct result the proper pressure at the nozzle is not formed. Foam stability is worsened, the distribution and size of the bubbles will not be adequate Cells cannot hold their spherical shape; larger diameters are torn off, causing poor surface quality. This phenomenon is also present in the recycling of rPET, which is a serious problem as the raw material and the quality of the finished product also deteriorate.

In the case of the study, PET re-granulate was dried for 12 hours at $140^{\circ} \mathrm{C}$. This is due to the humidity of the raw material; it has to be less than $0,004 \%$ for injection moulding. Chain extensions to the base material are added in addition to the chemical foaming agent. This process connects chains and improves mechanical properties and increases viscosity [8] (Fig. 2).
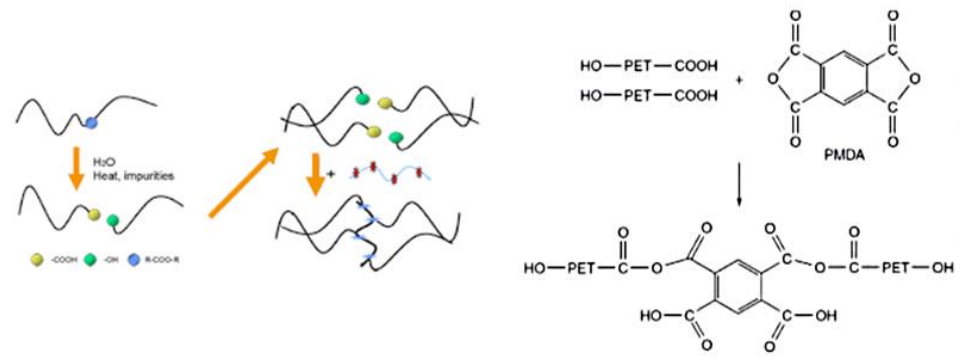

Figure 2. The principle and actual operation of the chain extension additive [6]

\subsection{Injection moulding}

One of the most productive processing technologies is injection moulding; this process typically produces thin-walled products ranging from a few millimetres to several meters in length [8].

In the case of chemical foaming moulding, structural foam is produced because the shell of the product which is in contact with the wall of the tempered tool is generally solid [9]. Towards the core the foamed proportion increases. As to the size of cells, it can be observed that the cell diameters are larger in the middle of the product. During the chemically-foamed injection moulding process, self-closing nozzles must be used and greater compression pressure to prevent the material from foaming during plasticization. 


\subsection{Breathing-mould technique}

In order to achieve the appropriate foam level, the pressure differences can be influenced by the mould opening or breathing tool technique. During this process, the polymer mixed with the blowing agent is injected into the mould cavity where the compact surface layer of the piece is formed during the cooling. Then, with the minimal opening of the tool the space increases and the pressure decreases, so that the still molten material is foaming. The tool opening depends on the setting of the tool cavity and the injection moulding machine. In the experiments, a $0.3 \mathrm{~mm}$ opening of the mould was used to produce the test specimens [10] (Fig. 3).

\subsection{Aims and objectives}

At the start of our research, the goal was to create a foam structure for recycled polyethylene terephthalate. In addition to the appropriate injection moulding parameters, the available crystallized blue bottle re-granulate with $4 \%$ foaming agent is suitable for forming a closed cell foam structure.

After this our objective was improving the manufactured specimens to achieve the goal: lower density and better mechanical properties. In the comparisons no plain rPET specimens are included, as the current objective is to create better and better foamed samples.
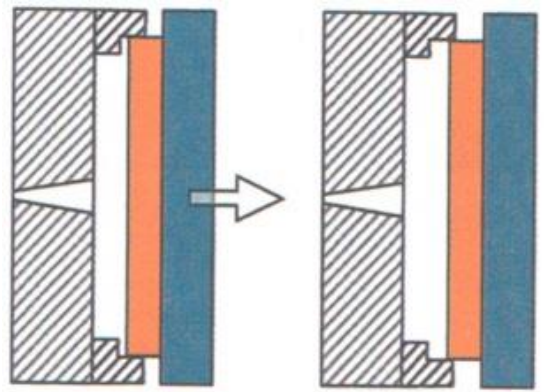

Figure 3. Breathing-mould technique [11]

\section{Used materials and methods}

During the experiments, commercially available blue crystallized PET re-granulate (rPET) was used. The chemical blowing agent was Tracell IM 7200. During injection moulding, 500g of rPET was mixed with $4 \mathrm{wt} \%$ of chemical blowing agent (CBA). According to the literature research and testing the $4 \mathrm{wt} \%$ blowing agent produces the best results. The CESA Extend NCA0025531-ZA chain extender was mixed with the substance at $2 \mathrm{wt} \%$ ratio. Impact modifier used in the testing has been from DuPont at the substance mixture of $10 \mathrm{wt} \%$.

During the injection moulding, a dumbbell specimen and a type of thermoplastic polymer material was produced. The Arburg ALLROUNDER 420C Golden Edition injection moulding machine was used to produce the specimens (Table 1). The traditional moulding technology was combined with the breathing tool technology. To achieve the 
right tool temperature the samples were tested at $25^{\circ} \mathrm{C}, 35^{\circ} \mathrm{C}$ and $45^{\circ} \mathrm{C}$. The foam structure of the manufactured specimens was examined by YXLON Y.CT Modular Industrial CT. The impact resistance was measured on CEAST 65-45,000 impactors according to MSZ EN ISO 179 standard. The tensile tests were carried out on the INSTRON 5582 universal testing machine according to MSZ EN ISO 527.

Table 1. Injection moulding parameters

\begin{tabular}{|c|c|c|}
\hline Description & Unit & Value \\
\hline Clamp force & $\mathrm{kN}$ & 150 \\
\hline Nozzle Temperature & ${ }^{\circ} \mathrm{C}$ & 260 \\
\hline Injection Pressure & $\mathrm{bar}$ & 650 \\
\hline Injection Speed & $\mathrm{cm} 3 / \mathrm{s}$ & 30 \\
\hline Holding Pressure 1 & $\mathrm{bar}$ & 150 \\
\hline Holding Pressure 2 & $\mathrm{bar}$ & 50 \\
\hline Holding Time 1 & $\mathrm{sec}$ & 2 \\
\hline Holding Pressure 3 & $\mathrm{bar}$ & 20 \\
\hline Holding Time 2 & $\mathrm{sec}$ & 1 \\
\hline Residual Cooling & $\mathrm{sec}$ & 0 \\
\hline Intermediate Mould Gap & $\mathrm{mm}$ & 0.3 \\
\hline Mould Open Delay & $\mathrm{sec}$ & 20 \\
\hline Mould Temperature & ${ }^{\circ} \mathrm{C}$ & 35 \\
\hline
\end{tabular}

\subsection{Evaluation of results}

In our laboratory research, the foam structure, the density and the mechanical properties of the specimens were tested.

\subsection{Weight, volume and density measurement}

In our laboratory research, the extent to which the temperature of the tool temperature is influenced by the density of the undeclared rPET had been tested.

The results showed that the tool temperature, if only to a small degree, had an impact on the density of the specimen. The average $35^{\circ} \mathrm{C}$ injection moulded specimens were $3.8 \%$ higher at $25^{\circ} \mathrm{C}$ and $3.1 \%$ higher in $45^{\circ} \mathrm{C}$. Thus, to achieve optimum cell formation, it is advisable to temper the tool to $35^{\circ} \mathrm{C}$. (Fig. 4). By means of the foaming and breathing technology, the material fills the tool cavity, but there is some degradation and a decrease in surface quality. The degradations are visible to the naked eye. The reason we used the $35^{\circ} \mathrm{C}$ tool temperature is as, this proved to be the most effective in terms of cell forming; this is where the most cells have formed and solidified. 


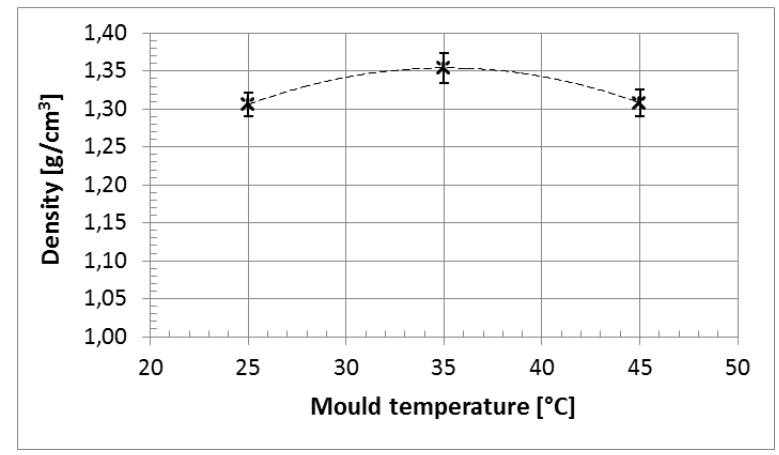

Figure 4. The effect of tool temperature on density in case of rPET

One of the beneficial effects of foaming is the decrease in weight. Because of the established cell structure, the density of the test samples decreases. On average, the density of foamed rPET is $14.82 \%$ lower. The density of the rPET expanded with the chain extender was $12.37 \%$ less than the non-foamed rPET.

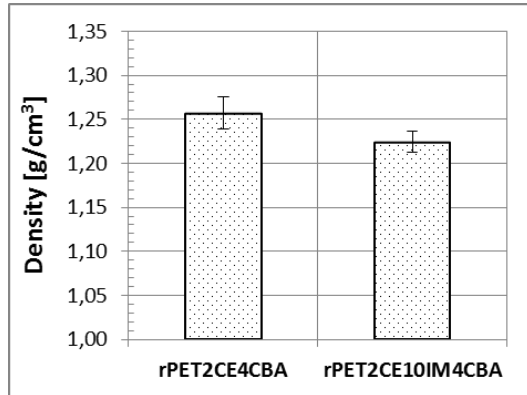

Figure 5. The effect of foamed blend composition on density

I compared the density of the foamed rPET containing the impact modifier and chainextending agent against only the chain-extended ones. It is apparent from the results that the impact resistance modifier further reduced the mass along with the density (Fig. 5). Concerning cell formation, it can be stated that a better structured cell layout is obtained with increased impact resistance. For density measures the pre-tested specimen has provided data; height, width, length and weight have been measured, from this density can be calculated as follows (1):

$$
\rho=\frac{m}{V},
$$

where $\rho\left[\mathrm{g} / \mathrm{cm}^{3}\right]$ is density, $\mathrm{m}[\mathrm{g}]$ is weight of the specimen, $\mathrm{V}\left[\mathrm{cm}^{3}\right]$ is the volume of specimen.

\subsection{Foam structure}

After the examination of the foam structure on the specimens with a CT device; Figure 6 shows a 3D image of a 3mm section of rPET specimen with $4 \mathrm{wt} \%$ chemical blowing agent. The average porosity of the product is $15.05 \%$. The average wall thickness of the 
shell wall is $0.526 \mathrm{~mm}$. The cell density of the test samples is $12.67 \mathrm{pcs} / \mathrm{mm}^{3}$ on average. The average cell diameter is $283 \mu \mathrm{m}$.

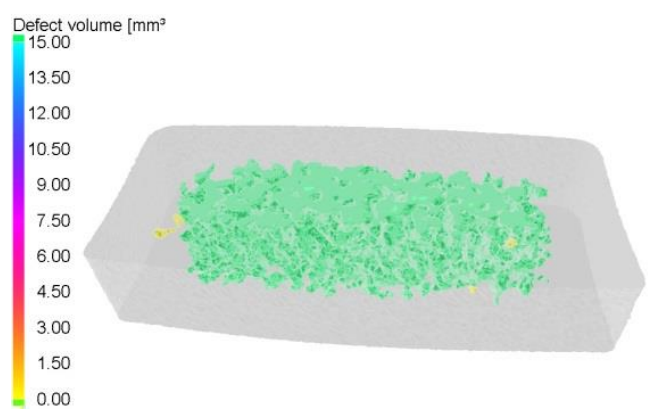

Figure 6. CT images of rPET4CBA

Figure 7 shows the 3D image of a $3 \mathrm{~mm}$ section of rPET with $4 \mathrm{wt} \%$ foaming agent and $2 \mathrm{wt} \%$ chain extender. When calculating the average porosity, a lower value than the test of the no-load test specimens was measured, this value was $12.42 \%$. This is due to the fact that in case of full hollow volume testing, we also received lower values, both cell number and cell density decreased with the chain enhancer. With respect to cell density, $1.116 \mathrm{pcs} / \mathrm{mm}^{3}$ is the rate of decline. Not only cell numbers but cell diameters are smaller. In the product mixed with the chain extender, the cells have an average diameter of $273 \mu \mathrm{m}$. However, the standard deviation of the average cell diameter is relatively high, which is because the core layer has unevenly spread throughout the process.

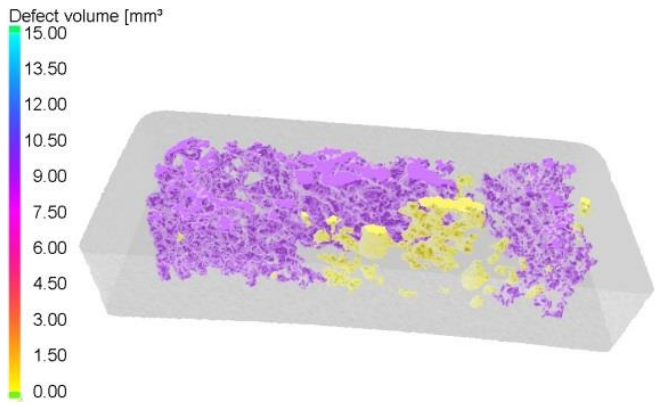

Figure 7. CT images of rPET2CE4CBA

\subsection{Mechanical testing}

We have investigated the effect of the chain extender on the mechanical properties. The results are summarized in Figure 8 . As it did not produce the desired results, the mechanical properties with a $10 \mathrm{wt} \%$ of impact modifier (IM) were compared.

The value of the Young modulus calculated from tensile test results was $47.8 \%$ greater than the average of the measured results. After the linearity of tension and deformation ceases, the rPET probes become instable before the formation of the neck. The deformation would continue in less rigid way, more disorganized structure, but the material that became instable due to the cells suddenly crashed before the steady flow stage began. Because of the disorderly cell formation, the blend-blown impact exhibits 
lower tensile strength. No real elongation was observed in the foamed rPET examination because of the rapid fracture. It can be concluded from the results that although there was a slight increase, but due to the uneven cell formation due to the chain extender, there was a lower elongation. However, the impact resistance increased the elongation value more than twice. Using the impact modifier, a more stable cell structure can be achieved.

In the Charpy impact test, I did not make any notches on the foamed rPET specimens because of the crystal structure and the cellular structure, without the brittle fracture. It can be noticed that the resistance to impact of the $2 \mathrm{wt} \%$ chain extending agent is greater than that of the foam. The impact modified specimens have three times bigger resistance against dynamical stress as chain extended specimen and seven times greater as pure foam specimen. Thus, it can be stated that the practical use of the impact resistance extender has shown a positive result.

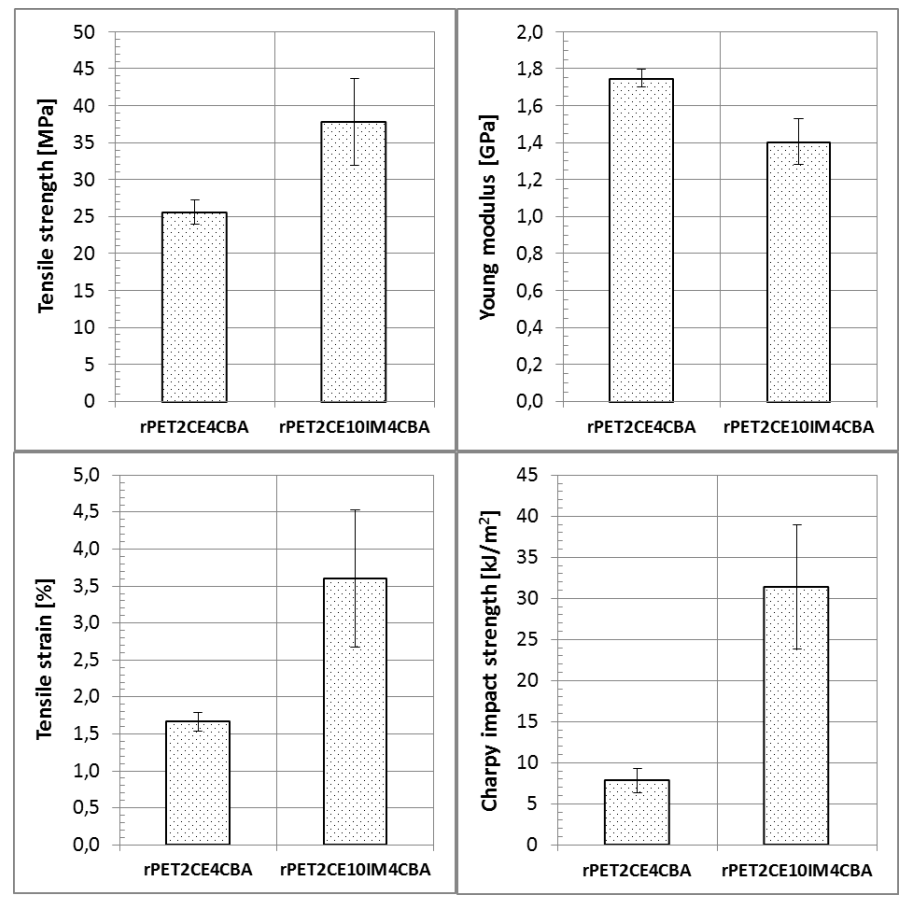

Figure 8. The mechanical properties of foamed rPET

\section{Conclusion}

The aim of the research was to increase the quality of recycled PET with chemical foaming. During our laboratory experiments, we examined the effect of the tool temperature on the injected un-foamed rPET properties. Previous tests have shown that the modification of temperature, changes the mechanical properties of rPET; even if only marginally. By reducing the temperature of the tool, it is more apparent, while the temperature increases resulted tougher plastic. Before processing, the raw material, it 
must be dried sufficiently to achieve the appropriate rheological properties. Negative effect that there is some degradation and there is a decline in surface quality, but the increase in density and material utilization as well as a positive effect on weight can be achieved. The use of chain extenders did not produce the desired result. However, the combined application of the impact resistance modifier and the chain extender showed as a positive change in all measured mechanical properties. The new blend showed a seven times better resistance to the initial rPET foam in Charpy's impact test. In the present phase of the research, the test specimens are partly in line with expectations, due to the formation of the cell structure, the result is decreased density. As they are under development in morphological tests positive results were obtained when testing new mixtures. With new chemical blowing agents to test the mixture further mechanical tests are needed. Our further intent is to optimize mechanical properties.

We are confident that after completing the full research, we will define the precise composition and production steps of a substance, which will be a milestone not only for innovative industrial developments but also for environmental protection.

\section{Acknowledgements}

The publishing of this paper was supported by the ÚNKP-16-1 New National Excellence Program of the Ministry of Human Capacities.

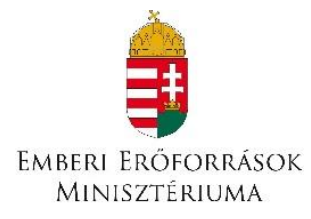

\section{References}

[1] Bach C, Dauchy X, Chagnon M, Serge E: Chemical migration in drinking water stored in polyethylene terephthalate (PET) bottles: a source of controversy, HAL, France 2012

[2] Coccorullo I, Maio L, Di Montesano S, Incarnato L: Theoretical and experimental study of foaming process with chain extended recycled PET, Express Polymer Letters, Vol. 3, No. 2, pp. 84-96, 2009

[3] Ronkay F, Molnár B, Dogossy G: The effect of mold temperature on chemical foaming of injection molded recycled polyethylene-terephthalate, Thermochimica Acta, Vol. 651, pp. 65-72, 2017

[4] Brandrup J, Immergut EH, Grulke EA: Polymer Handbook, Fourth edition, John Wiley \& Sons Inc, 1999

[5] Dobrovszky K: Upcycling of polymer waste from automotive industry, Periodica Polytechnica - Mechanical Engineering, Vol. 55, No. 2, pp. 73-77, 2011

[6] Belofsky H. Plastics: Product Design and Process Engineering, HanserGardner. Munich-Cincinnati, 1995

[7] Chunxin Z, Florence B, Christian B, Richard M, Christopher L, Hristo A, Albert Y: Highly Porous Polyhedral Silsesquioxane Polymers, Synthesis and Characterization, Journal of the American Chemical Society, Vol. 120, No. 33, pp. 8380-8391, 1998 
[8] Molnár B: The Effect of Technological Parameters on the Foaming of Injection Molded, Recycled PET, Acta Technica Jaurinensis, Vol. 7, No. 1, pp. 1-10, 2014

[9] Molnár B, Ronkay F: Investigation of Morphology of Recycled PET by Modulated DSC, Materials Sciences Forum, Vol. 885, pp. 263-268, 2017

[10] Molnar B, Ronkay F: Time dependence of morphology and mechanical properties of injection moulded recycled PET, International Polymer Processing, Vol. 32, No. 2, pp. 203-208, 2017

[11] Malnati P.: Innovative Trends in Hybrid Molding Processes, Plastics Engineering, Vol. 73, No. 5, pp. 32-37, 2017 